\title{
A Novel Adaptive Neural MPPT Algorithm for Photovoltaic System
}

\author{
S. A. Allahyari ${ }^{1}$, N. Taheri ${ }^{2 *}$, M. Zadehbagheri ${ }^{3}$ and Z. Rahimkhani ${ }^{4}$ \\ ${ }^{1}$ Mehriz Branch, Islamic Azad University, Mehriz, Iran \\ ${ }^{2}$ Electrical Engineering Department, Technical and Vocational University, \\ Sabzevar, Iran \\ *Email: ntaheri@tvu.ac.ir \\ Phone: +985147227367 \\ ${ }^{3}$ Yasouj Branch, Islamic Azad University, Kohgiloyeh \& Bovirahmad Province, \\ Yasouj, Iran \\ ${ }^{4}$ Sarvestan Branch, Islamic Azad University, Sarvestan, Iran
}

\begin{abstract}
This paper presents a novel adaptive neural network (ANN) for maximum power point tracking (MPPT) in photovoltaic (PV) systems under variable working conditions. The ANN-based MPPT model includes two separate NNs for PV system identification and control. NNs are trained by using of a novel back propagation algorithm in pre/post control phases. Because of online optimal performance of NNs, the proposed method, not only overcome the common drawbacks of the conventional MPPT methods, but also gives a simple and a robust MPPT scheme. Simulation results, which carried on MATLAB, show that proposed controller is the most effective in comparison with conventional MPPT approaches.
\end{abstract}

Keywords: Photovoltaic systems; adaptive neural networks; MPPT algorithm.

\section{INTRODUCTION}

Nowadays, consumption of electrical energy has been developing very rapidly and has become an important issue for human kind. Therefore, experts make effort to find new ways to produce clean and renewable energy [1]. Renewable energy is the energy, which comes from natural resources such as sunlight, wind, rain, tides and geothermal heat. These resources are renewable and replenished naturally. Some advantages of these resources are availability and accessibility, having less environmental damage rather than fossil fuels and having the ability of operation in remote areas of the network [1-3].

Among all renewable energies, solar energy, which is available in all around the world, seems an affordable criterion especially in low power application. This is because of the lack of fuel costs, the scalability in power and the simplicity and small amounts of maintenance required by the PV system [3-5]. Notice that, total energy received from the sun by the earth, is not comparable with those amounts of energy, which are consumed by human and in this point of view, solar energy can be a large and an appropriate source to make satisfaction in human energy demands.

However, in despite of the mentioned advantages, generation of per watt solar power is more expensive than its fossil fuels counterpart because of its capital investment. Energy conversion efficiency and dependency to environmental factors are also main obstacles in using of PV technology in large scales [6-7]. Of course, to solve 
these drawbacks, development of power electronic technology and using MPPT algorithms can be used to extract maximum possible power from PV module. Considering all affecting power electronic factors such as material efficiency, integration, and structural configuration, boosting the MPPT capability is the most economical way of enhancing the efficiency of the overall PV system [7-8]. MPPT can recognize MPP position i.e. favorable operating voltage or current in order to have maximum output power.

Different techniques and methods are proposed to implement MPPT algorithm. These methods include perturb and observe ( $\mathrm{P} \& \mathrm{O}$ ) [9], incremental conductance (IC) [10], hill climbing (HC) [11], fractional open-circuit voltage [12], fractional shortcircuit current [13], neural network [14], fuzzy logic methods [15], and genetic algorithms [16]. These techniques are different from some aspects such as complexity of implementation, required sensors, speed and accuracy in convergence, provided efficiency, oscillations around MPP.

Recently using of neural networks in power system applications have been increased. This is because of learning ability of neural network, which allows handling different process without having any case of knowledge about the nature of solved problem. Neural networks can detect complex nonlinear relationships between dependent and independent variables. It is possible to design an adaptive neural network, which can adapt itself to variable conditions of a process.

The main contribution of this paper is to propose an approach using a neural network in order to perform MPPT control. Proposed MPPT controller includes two distinct neural networks i.e. neural identifier and neural controller. This configuration can adapt itself to different atmospheric conditions and produce the most appropriate duty cycle for power converter. Required data for generating the ANN model are captured using the principle of perturbation and observation method.

\section{MODELLING OF PHOTOVOLTAIC CELLS}

Photovoltaic system converts light directly into electricity. Materials inside the PV arrays absorb solar energy and release electron charges which in this way, it is possible to generate electrical power. Figure 1 shows an equivalent schematic of a PV cell [17]. It uses materials, which absorb photons of lights and release electrons charge. It can be used for making electric generators. PV array consists of strings connected in parallel to supply a higher current and reach a given power. Each string is formed of a specific PV module number connected in series in order to obtain the required voltage. PV modules are built by connecting solar cells in series with the purpose of getting a sufficient voltage level and increasing the nominal power of the PV array system [18]. The equivalent model of a PV cell is shown in Figure 1. Generated current in PC cell can be considered as a function of photo-generated current, diode current and shunt current as in Eq. (1) and (2).

$$
\begin{aligned}
& I=N_{p}\left(I_{p h}-I_{0}\left[e^{\frac{q\left(V_{p v}+R_{s} I\right)}{A k T N_{s}}}-1\right]-\frac{\left(V_{p v}+R_{s} I_{0}\right)}{N_{s} R_{p}}\right) \\
& I_{p h}=\frac{G}{1000}\left(I_{s c}+k_{i}\left(T-T_{r}\right)\right)
\end{aligned}
$$


where, I and V show the PV array output current and voltage respectively. $\mathrm{N}_{\mathrm{s}}$ and $\mathrm{N}_{\mathrm{p}}$ represent the number of PV cells connected in series and parallel respectively. Q is the charge of electron, $I_{p h}$ is the light current that is proportional to solar irradiance according to Eq (2). $I_{0}$, is the saturation current, $A$ is diode ideality factor, $\mathrm{k}$ is the Boltzmann's constant and T is the PV cell temperature in kelvins. $\mathrm{I}_{\mathrm{sc}}$ is cell short circuit current at reference temperature and irradiation. The $\mathrm{k}_{\mathrm{i}}, \mathrm{T}_{\mathrm{r}}$ and $\mathrm{T}$ are short-circuit current temperature coefficient, cell reference temperature and solar irradiation respectively [17-18].

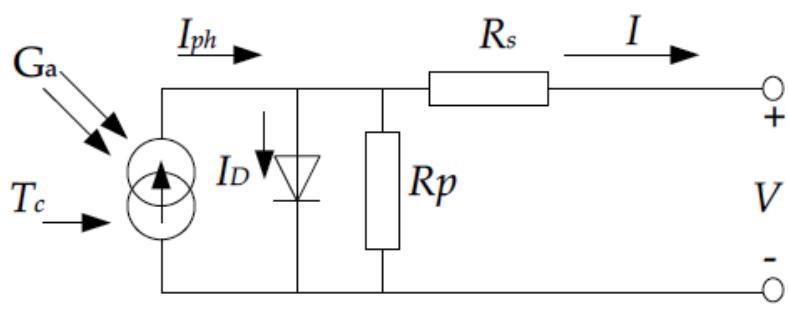

Figure 1. Equivalent circuit for PV cell.

\section{CONVENTIONAL PERTURB AND OBSERVE (P\&O) MPPT}

The $\mathrm{P} \& \mathrm{O}$ algorithm is called "hill-climbing" also, but both algorithms are referring to the same algorithm depending on how it is implemented. In hill-climbing algorithm, perturbation is applied to the duty cycle of the power converter but in $\mathrm{P} \& \mathrm{O}$ method, perturbation will be applied to the output voltage of PV arrays [17-19].

In the case of the hill-climbing, perturbing the duty cycle of the power converter modifies the voltage of the DC link between the PV array and the power converter, so both names refer to the same technique. In P\&O, algorithm sign of perturbation and power deviations is used to make decision about what the next perturbation should be. According to Figure 2(a) and (b), the left side of MPP, increasing the voltage resulted in an increase in power on the right side of MPP, decreasing the voltage resulted in an increase in power.

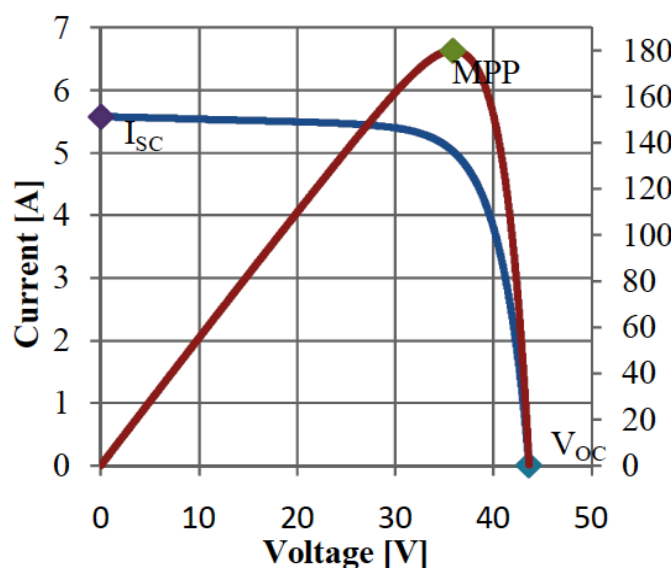

(a)

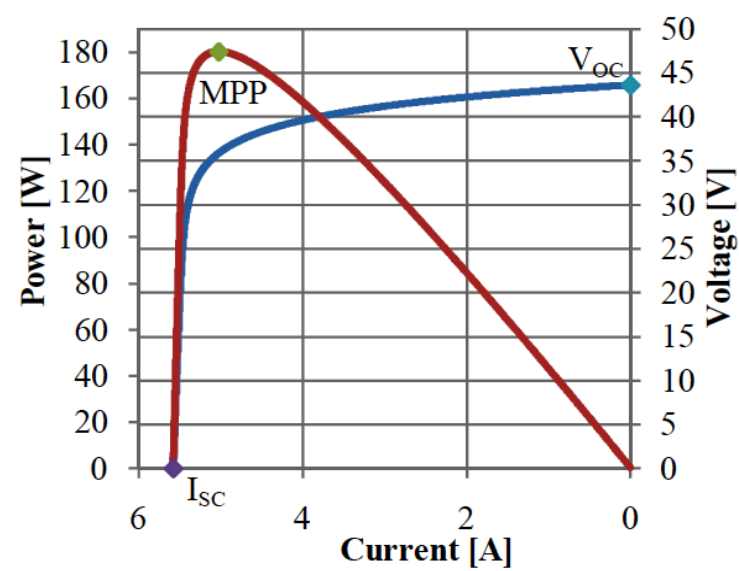

(b)

Figure 2. PV characteristics curves of (a) current-voltage and; (b) power-current. 
Based on $\mathrm{P} \& \mathrm{O}$ algorithm in Figure 3, when an increment in the power is observed, the perturbation should be kept in same direction while decrement in power changes the direction of perturbation. The process is repeated until the MPP is reached. Then the operating point oscillates around the MPP. This is a most important drawback of this algorithm [19-20]. In next section of this paper, adaptive neural controller based on MPPT is proposed to enhance shortcomings of $\mathrm{P} \& \mathrm{O}$ method.

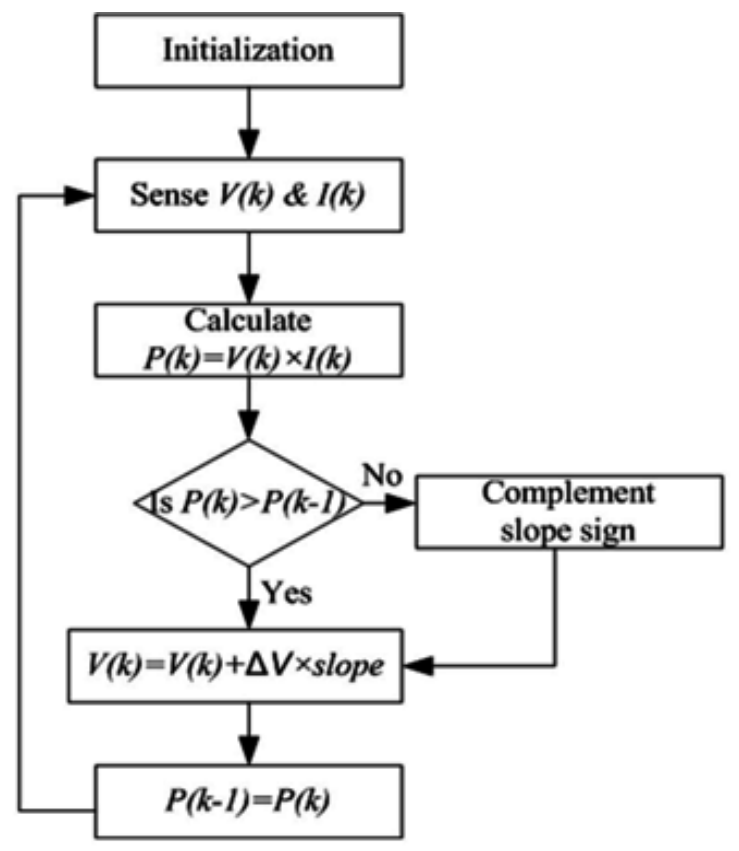

(a)

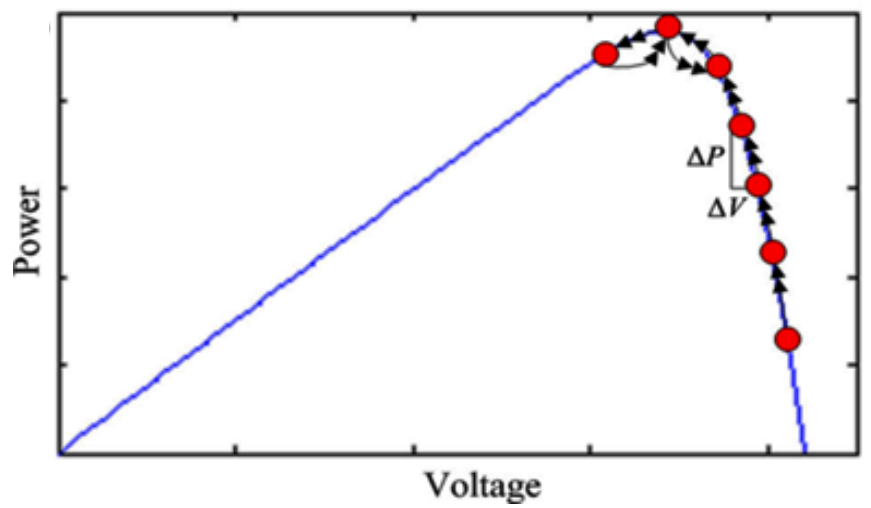

(b)

Figure 3. (a) P\&O flowchart and; (b) characteristic curve for $\mathrm{P} \& \mathrm{O}$ algorithm.

\section{PROPOSED MPPT BASED ON ADAPTIVE NEURAL CONTROLLER}

As mentioned in previous section, PV system has nonlinear characteristic and any change in environmental parameters can affect the output voltage and current of PV. Therefore, it is desirable that identifies PV characteristic in any time step to implement the most effective MPPT algorithm. In this part of paper, using an adaptive nonlinear neural controller is proposed to implement a dynamic MPPT. 
The simplest definition of neural networks is as follows: "a computing system made up of a number of simple, highly interconnected processing elements, which process information by their dynamic state response to external inputs". Neural networks are usually composed of several layers. In each layer, there are interconnected neurons, which include activation function.

Data are applied to the input layer and after that will be communicated with one or several hidden layers. In neural networks, actual processing is done via a system of weighted 'connections'. Notice that hidden layers are connected to the output layer, which produce final output of network. Modifying of weights is achieved by using many different learning rules like "delta rule". The most common class of neural networks often utilizes the delta rule. This rule works based on error back propagation algorithm.

Figure 4 shows the proposed MPPT neural controller for PV application. This adaptive neural controller includes two separated neural networks as identifier and controller. Neural controller is used to generate duty cycle signal for DC chopper and neural identifier is used to model dynamic of the PV system and to adapt the neuro controller parameters. On the other hand, Neural identifier is a feed forward multilayer perceptron while neural controller is working based on recurrent neural networks. Output components of real PV system and neural controller can be used to train neural identifier based on error back propagation method. Dash lines in Figure 4 show the back-propagation paths to update the weights of the neural identifier and controller.

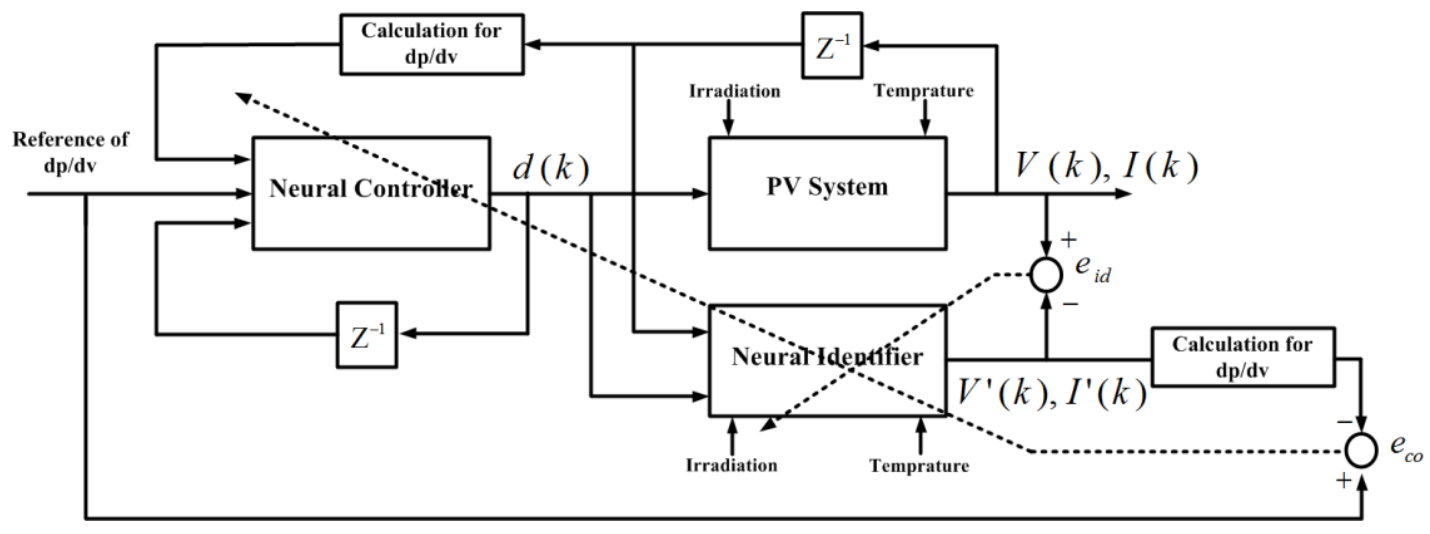

Figure 4. Proposed adaptive neural controller based on MPPT.

Cost function for identifier, which must be minimized to train neural network, is defined as sum of square difference between voltage and current of real PV system and voltage and current of identifier in each time sample respectively as in Eq. (3).

$\mathrm{e}_{\mathrm{id}}=\frac{1}{2}\left\{\left(\mathrm{~V}(\mathrm{k})-\mathrm{V}^{\prime}(\mathrm{k})\right)^{2}+\left(\mathrm{I}(\mathrm{k})-\mathrm{I}^{\prime}(\mathrm{k})\right)^{2}\right\}$

Neural controller, which is a recurrent neural network, has important task. It is responsible to produce appropriate duty cycle $(\mathrm{d}(\mathrm{k}))$ for power converter to reach MPP with good level of accuracy. In addition to the power deviation samples, which are calculated using PV system real data, past outputs of controller are fed to the network. The neural controller is trained using back propagation error method. For this network, error is calculated as in Eq. (4). 
$\mathrm{e}_{\mathrm{co}}=\frac{1}{2}\left\{\left(\frac{\mathrm{dp}}{\mathrm{dv}_{\mathrm{ref}}}-\frac{\mathrm{dp}}{\mathrm{dv}}\right)^{2}\right\}$

Notice that, to train neural controller, error in Eq. (4) must back propagate using neural identifier path. For getting the best result, it is essential to have $\frac{\mathrm{dp}}{\mathrm{dv}_{\text {ref }}}=0$

\section{Neural Identifier}

The neural identifier is developed based on series parallel auto regressive moving average (NARMA) model. Every output of identifier at time $\mathrm{k}+1$ depends on both past $\mathrm{n}$ values of output and $\mathrm{m}$ past values of inputs. Because of limitations in computations, the selected value for $\mathrm{m}$ and $\mathrm{n}$ should not be too large. Neural identifier is used in proposed control structure for two purposes: (a) identification of photovoltaic system and (b) training neural controller based back propagation error and delta rule. As shown in Figure 4, error of "dp" /"dv" deviation must back propagate using neural identifier to update connection weights in neural controller. There is no alternative to train neural controller. Structure of neural identifier is shown in Figure 5.

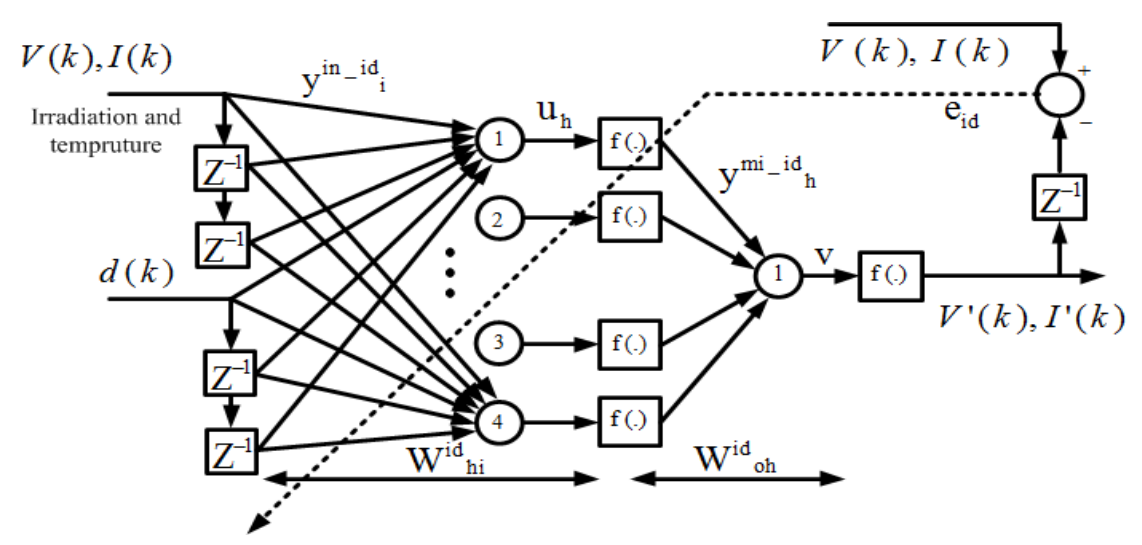

Figure 5. Structure for proposed adaptive identifier.

This network has four neurons at hidden and one at output layer. $\mathrm{F}$ is activation function that is hyperbolic tangent in this paper. Neural identifier is trained based on error back propagation method that described in detail as follows. Cost function is defined as Eq. (3). (V (k), I (k)) and $\left(\mathrm{V}^{\prime}(\mathrm{k}), \mathrm{I}^{\prime}(\mathrm{k})\right)$ and neural identifier outputs, respectively. By using of relative derivatives, it is possible to write Eq. (5) as:

$\frac{\partial \mathrm{E}_{\mathrm{id}}}{\partial \mathrm{w}_{\mathrm{oh}}^{\mathrm{id}}}=\frac{\partial \mathrm{E}_{\mathrm{id}}}{\partial \mathrm{e}_{\mathrm{id}}} \frac{\partial \mathrm{e}_{\mathrm{id}}}{\partial \widehat{\Delta \omega}} \frac{\partial \widehat{\Delta \omega}}{\partial \mathrm{v}} \frac{\partial \mathrm{v}}{\partial \mathrm{w}_{\mathrm{oh}}^{\mathrm{id}}}$

where $w^{i d}{ }_{\text {oh }}$ are used to show connected weights between output and hidden layer. Based on Eq. (5), sensitive coefficients of neuron in output layer are calculated and $\mathrm{w}_{\mathrm{oh}}^{\mathrm{id}}$ are updated based on Eq. (6). To update and corrects weights between input-output layers, sensitive coefficients of neurons in output layer must be used. 


$$
\mathrm{w}_{\mathrm{oh} \mathrm{New}}^{\mathrm{id}}=\mathrm{w}_{\mathrm{oh}}^{\text {id }} \text { Old }-\eta \frac{\partial \mathrm{E}_{\mathrm{id}}}{\mathrm{w}_{\mathrm{oh}}^{\text {id }}}
$$

\section{Neural Controller}

Figure 6 shows the structure of proposed adaptive neural controller in detail. This network is a recurrent neural network. A recurrent neural network (RNN) is a class of artificial neural network where connections between units form a directed cycle. This structure creates an internal state of the network, which allows it to exhibit dynamic temporal behavior. Unlike feedforward neural networks, RNNs can use their internal memory to process arbitrary sequences of inputs. Cost function to train this network is defined based on Eq. (4). To minimize cost function, we can write:

$$
\begin{aligned}
& \frac{\partial \mathrm{E}_{\mathrm{co}}}{\partial \frac{\mathrm{dp}}{\mathrm{dv}}}=-\frac{\mathrm{dp}}{\mathrm{dv}}=\mathrm{e}_{\mathrm{co}} \\
& \frac{\partial \mathrm{E}_{\mathrm{co}}}{\partial \mathrm{w}_{\mathrm{oh}}^{\mathrm{co}}}=\frac{\partial \mathrm{E}_{\mathrm{co}}}{\partial \mathrm{e}_{\mathrm{co}}} \frac{\partial \mathrm{e}_{\mathrm{co}}}{\partial \widehat{\Delta \omega}} \frac{\partial \widehat{\Delta \omega}}{\partial \mathrm{v}} \frac{\partial \mathrm{v}}{\partial \mathrm{w}_{\mathrm{oh}}^{\mathrm{co}}}
\end{aligned}
$$

$\mathrm{V}, \mathrm{w}_{\mathrm{oh}}^{\mathrm{co}}$ are the neural identifier output and the weights between output and hidden layer respectively.

$$
\mathrm{v}=\sum_{\mathrm{h}} \mathrm{w}_{\mathrm{oh}}^{\mathrm{id}} \mathrm{y}_{\mathrm{h}}^{\mathrm{mi}-\mathrm{id}}, \mathrm{y}_{\mathrm{h}}^{\mathrm{mi}-\mathrm{id}}=\mathrm{f}\left(\sum_{\mathrm{i}} \mathrm{w}_{\mathrm{oi}}^{\mathrm{id}} \mathrm{y}_{\mathrm{i}}^{\mathrm{mi}}{ }^{-i d}\right)
$$

$\mathrm{y}_{\mathrm{h}}^{\text {in-id }}, \mathrm{y}_{\mathrm{h}}^{\mathrm{mi}-\mathrm{id}}, \mathrm{w}_{\mathrm{hi}}^{\mathrm{id}}, \mathrm{w}_{\mathrm{oh}}^{\mathrm{id}}, \mathrm{i}$ and $\mathrm{h}$ are inputs, inputs to output layer, connection weights between input and hidden layer, weights between output and hidden layer, number of inputs and number of neuron in hidden layer of neural identifier, respectively, where;

$$
\frac{\partial \mathrm{v}}{\mathrm{w}_{\mathrm{oh}}^{\mathrm{co}}}=\frac{\partial \mathrm{v}}{\partial \mathrm{U}_{\mathrm{c}}} \frac{\partial \mathrm{U}_{\mathrm{c}}}{\mathrm{w}_{\mathrm{oh}}^{\mathrm{co}}}=\frac{\partial \mathrm{v}}{\partial \mathrm{y}_{\mathrm{h}}^{\mathrm{mi}}-\mathrm{id}} \frac{\partial \mathrm{y}_{\mathrm{h}}^{\mathrm{mi}-\mathrm{id}}}{\partial \mathrm{U}_{\mathrm{c}}} \frac{\partial \mathrm{U}_{\mathrm{c}}}{\mathrm{w}_{\mathrm{oh}}^{\mathrm{co}}}
$$

By using Eq. (8) to (10), it is possible to calculate the sensitive coefficients in output neuron of neural controller, correct the middle, and output weights of neural controller.

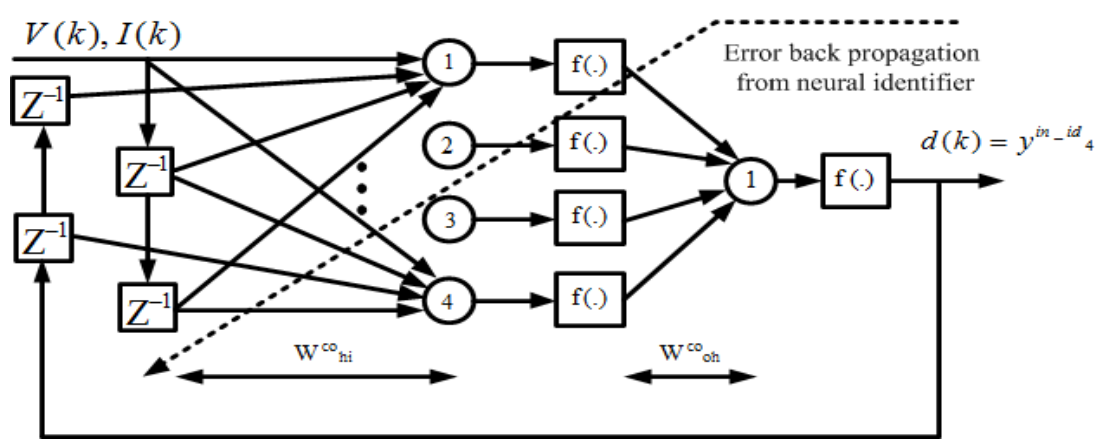

Figure 6. Structure of the online neural controller. 


\section{Training Process}

Training process is done in pre-control and post control phase. In pre-control phase, before implementation of proposed neural controller for PV system, neural identifier is trained offline. To reach this goal, PV system with P\&O MPPT algorithm is simulated and data of this system saved. Then, data are used to train neural identifier in offline mode. After this step, random inputs are given to the PV system and neural identifier simultaneously and system runs. The procedure, explained in section 1, is used to train network (Figure 7). In cascade with neural identifier, neural controller is trained. Connection weights of neural controller are corrected by using of neural identifier path, which is shown in Figure 8 by dashed line.

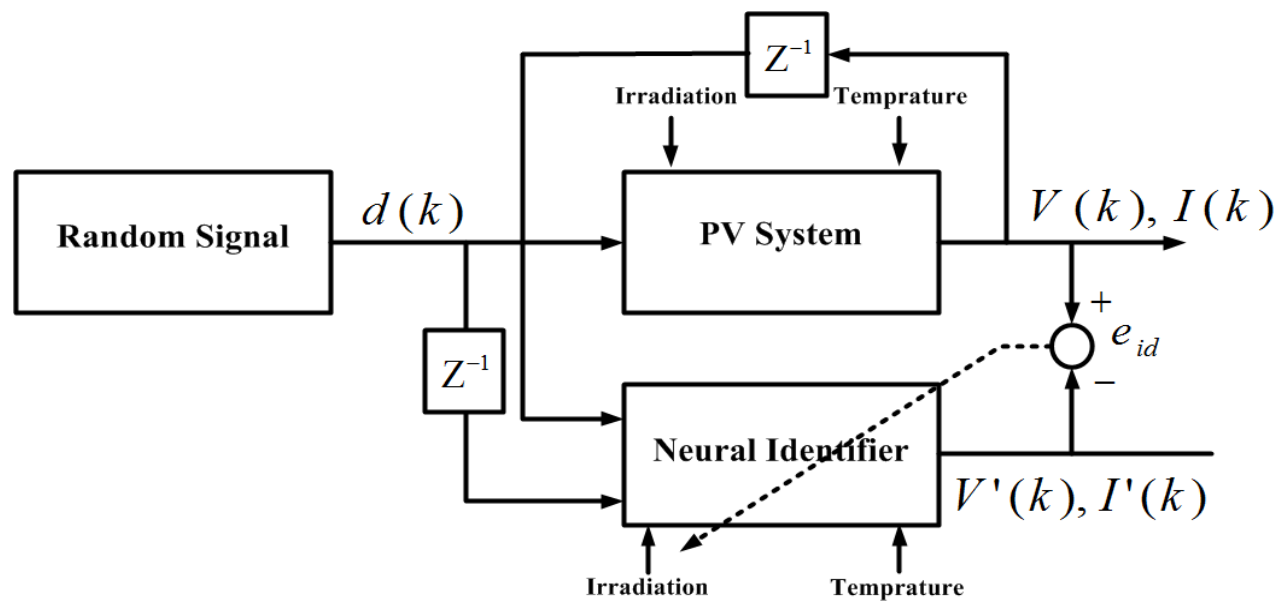

Figure 7. Training of neural identifier in pre-control phase.

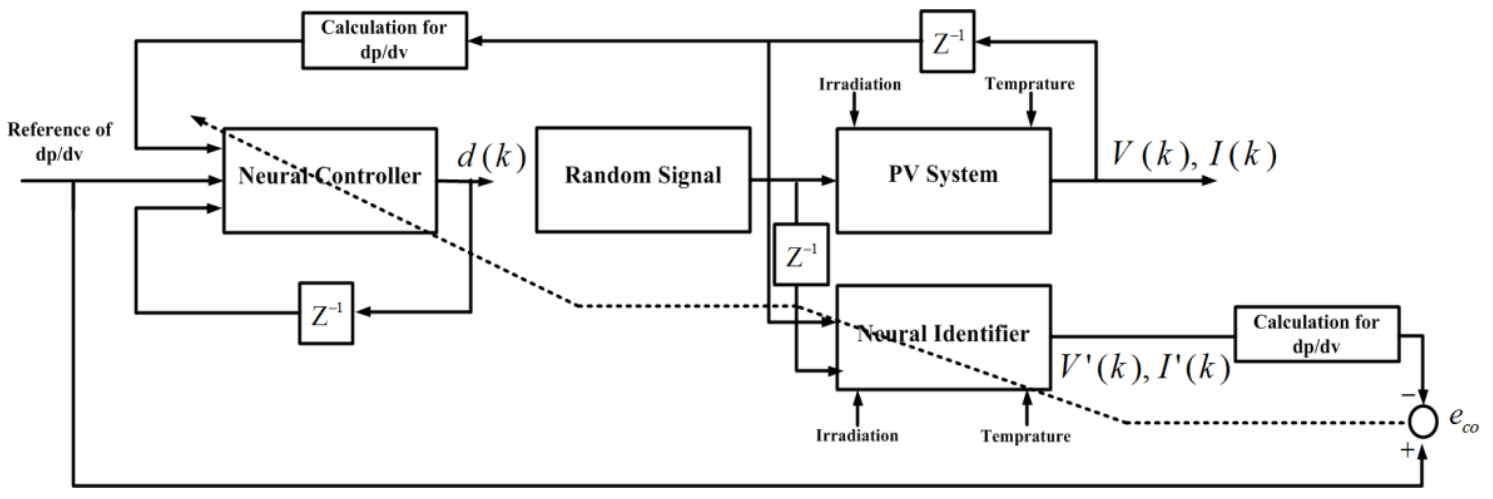

Figure 8. Training of neural controller in pre-control phase.

In post control phase this phase of training, both identifier and controller neural networks are used simultaneously. During this process, neural identifier training is achieved through the back-propagation error between real PV system and neural identifier outputs. After updating connected weights in neural identifier, training of neural controller is done by using identifier path. Finally, neural controller output is calculated and applied to the PV system. 


\section{SIMULATION RESULTS}

Simulation of the proposed control strategy is done in MATLAB/Simulink software with simulation step of $5 \times 10^{-6} \mathrm{~s}$. To implement neural controller and identifier, sfunction based on user-defined function is used. Changing of irradiance is selected as a disturbance for power system as it is shown in Figure 9. Notice that for any MPPT algorithm, slop change in irradiance is considered as a bad disturbance even more than a step change. In this study, temperature is constant in all time of simulation. A $100 \mathrm{~kW}$ PV array with $\mathrm{N}_{\mathrm{s}}=8, \mathrm{~N}_{\mathrm{p}}=61$ is considered for system simulation.

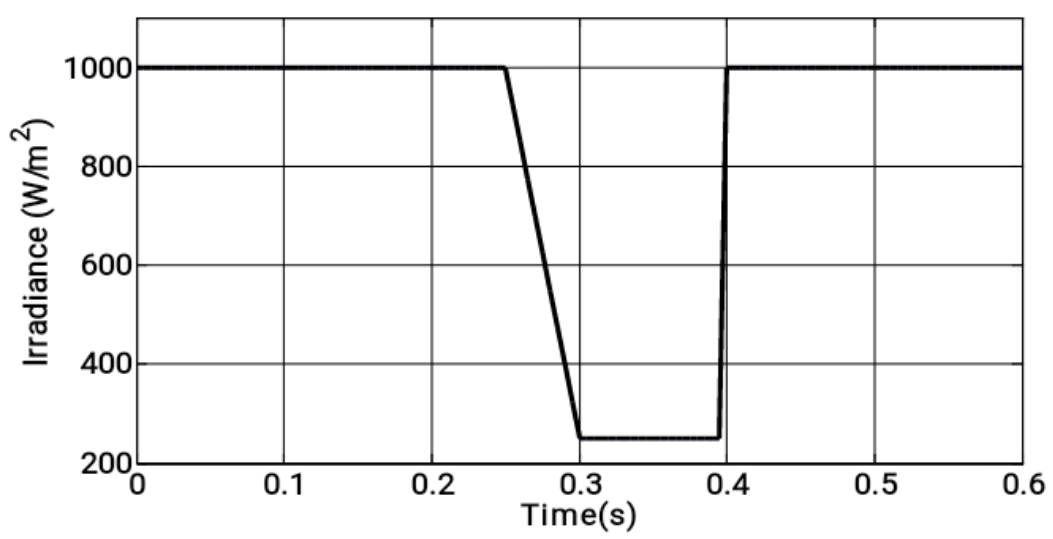

Figure 9. Changing of irradiance

Regarding the on-line training of the neural network, any change in the environmental parameters of the photovoltaic system is managed by the NNs identifier and controller, so that MPPT can be done in the best possible way. Whenever there is a change in the environmental parameters $t_{1}=0.2 \mathrm{~s}, \mathrm{t}_{2}=0.3 \mathrm{~s}$ and $\mathrm{t}_{3}=0.4 \mathrm{~s}$, deviation in photovoltaic system performance is approximated by the identifier network and a training signal is send to neural controller for online training. The controller training is done in such a way that the identification error is minimized and optimal MPPT signal is produced.

Figure 10 shows the terminal output voltage of PV system. By using of proposed neural controller, voltage is stabilized faster rather than using Classic $\mathrm{P} \& \mathrm{O}$ algorithm. Because the neural network, due to its simple computational structure, has a good speed in identifying and producing a MPPT control signal for DC-DC converter (contrary to $\mathrm{P} \& \mathrm{O}$ method, there is no need to differentiate in ANNs). Figure 11 shows that oscillations in modulation index are damped faster than classic P\&O MPPT method. In addition, it is observed that overshoot and under shoot in modulation index has been decreased when neural controller is used. 


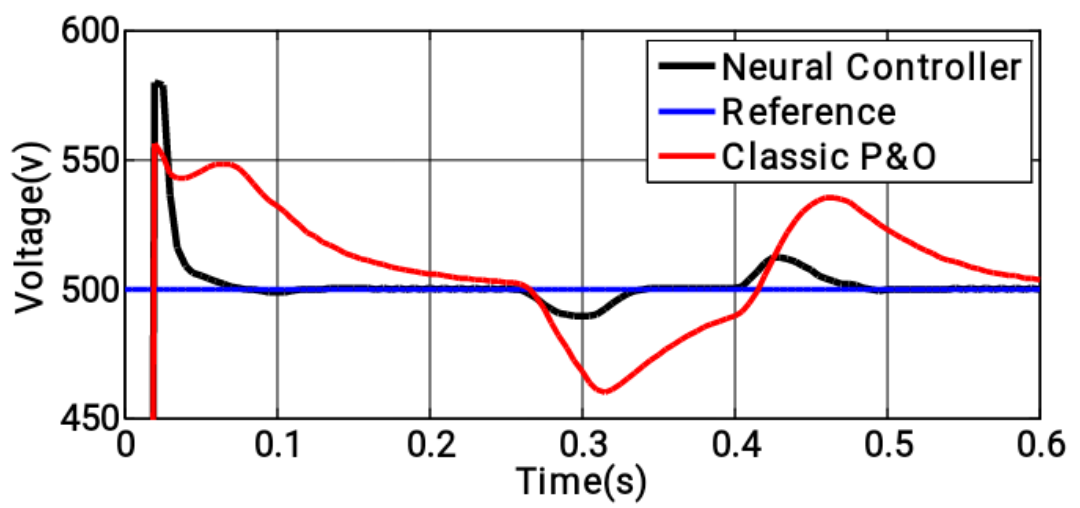

Figure 10. Output voltage of PV system.

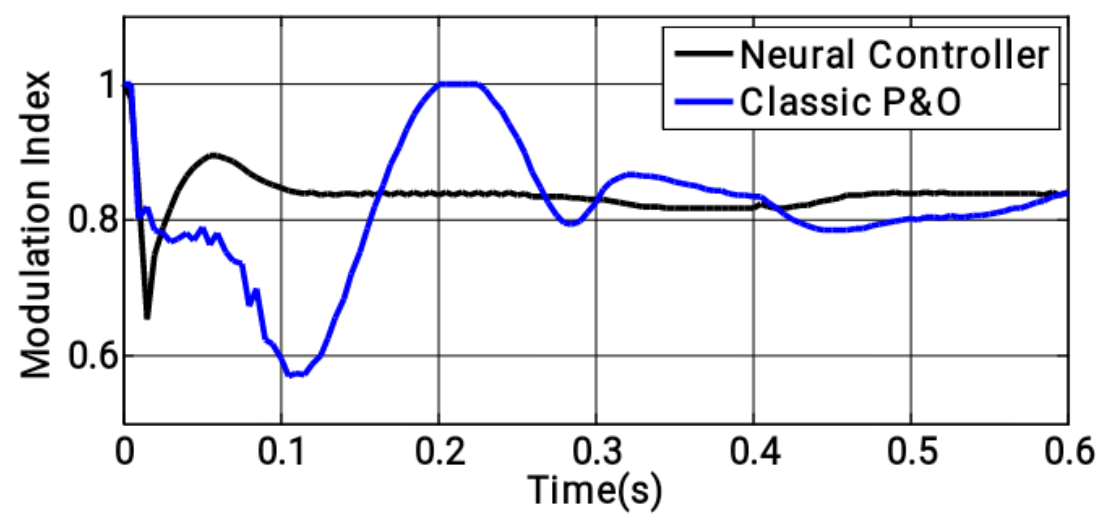

Figure 11. Modulation index of PV system.

Figure 12 shows reactive component of current, which is injected to the network. In classic $\mathrm{P} \& \mathrm{O}$, oscillations around zero are observed. That means some reactive power was exchanged between PV system (in power converter part) and network. However, when neural controller is used, exchanged reactive power is in a very low level. Injected active power by PV to the network is shown in Figure 13. Using of neural controller leads to a better performance of PV to generate active power. Based on Eq. (3) and Eq. (4), the proposed ANNs-MPPT method is used to minimize the errors of voltage, current and power of PV system. All mentioned errors should be minimized in the minimum sampling time. it is observed that voltage (Figure 10), power (Figure 13) current (Figure 12 and Figure 14) for ANNS-Based MPPT have less settling time. Figure 14 shows active component of injected current to the network by PV. Settling time and rising time for components are improved when neural strategy is used. Finally, in Figure 15 and Figure 16 connected weights deviation and performance of neural identifier are shown respectively. 


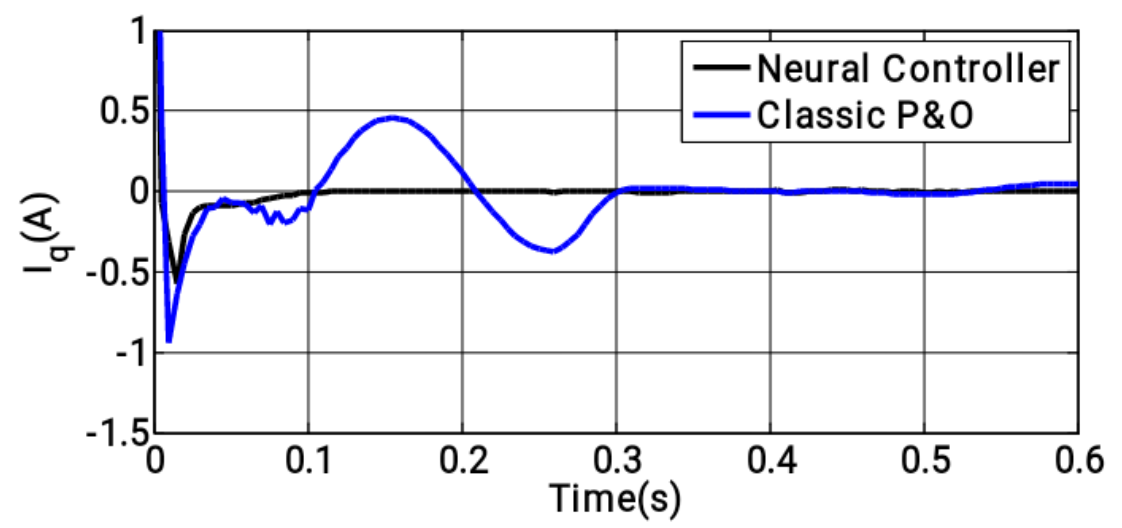

Figure 12. Reactive component of injected current by PV system.

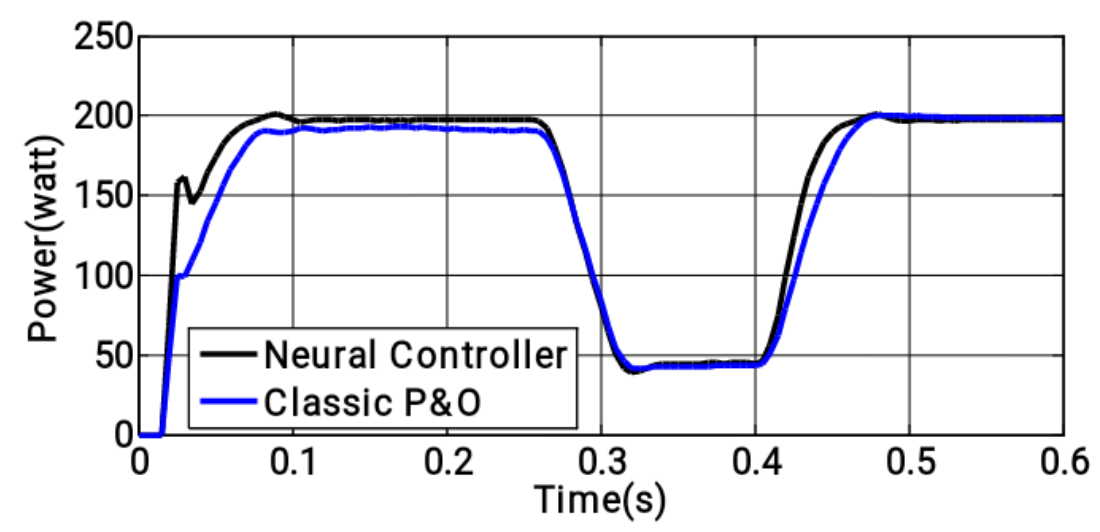

Figure 13. Injected active power by PV system.

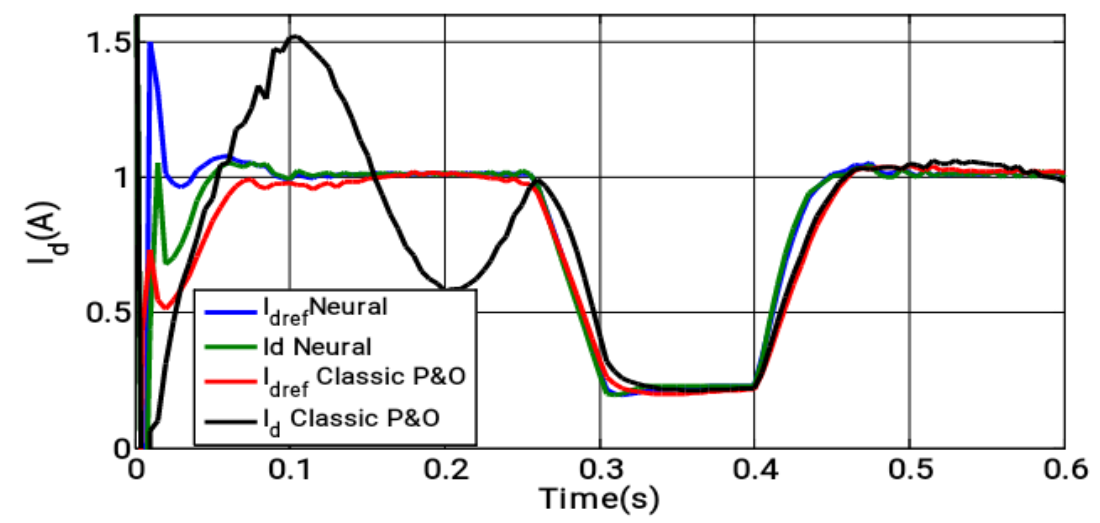

Figure 14. Injected active component of PV current. 


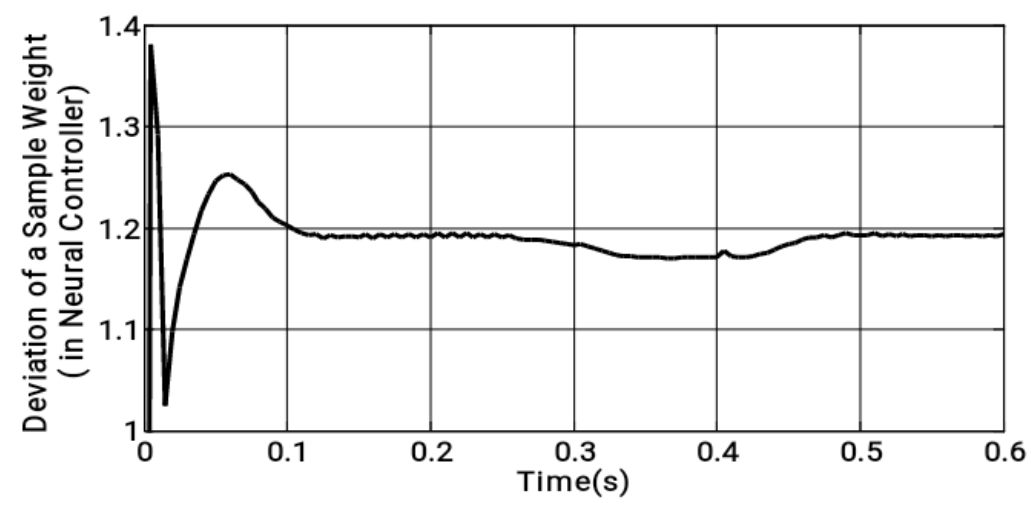

Figure 15. Weights deviation in neural controller.

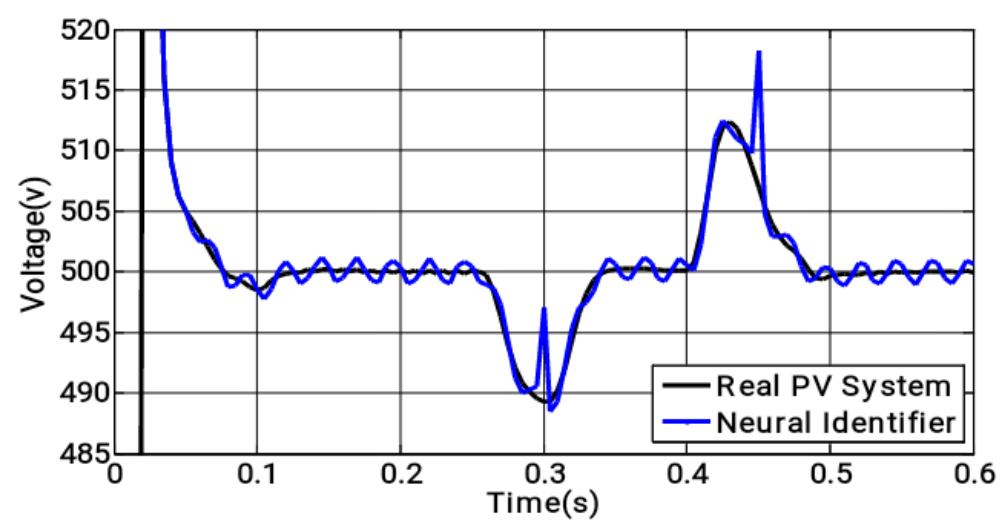

Figure 16. Neural identifier output for voltage.

\section{CONCLUSION}

In this paper, development of an adaptive neural controller to implement MPPT algorithm in photovoltaic systems is proposed. The proposed MPPT tracking method can estimate the MPPs of a PV system on-line using a neural network-based system. Proposed control strategy can solve environmental dependency of classical MPPT algorithm. Simulation results show that proposed neural MPPT algorithm is effective to obtain high quality operation of MPPT in different environmental condition. The simulation results clearly show that Neural MPPT method provides effective tracking of MPP so that maximum power can be extracted from the PV panel at changing weather conditions.

\section{REFERENCES}

[1] Sunanda S, Chandel SS. Review of recent trends in optimization techniques for solar photovoltaic-wind-based hybrid energy systems. Renewable and Sustainable Energy Reviews 2015; 50: 755-769.

[2] Somnath D, Akella AK. Power Flow Control of PV-Wind-Battery Hybrid Renewable Energy Systems for Stand-Alone Application. International Journal of Renewable Energy Research 2018; 8(1): 36-43. 
[3] Powell KM, Rashid K, Ellingwood K, Tuttle J, Iverson BD. Hybrid concentrated solar thermal power systems. Renewable and Sustainable Energy Reviews 2017; 80: 215-237.

[4] Lund PD, Lindgren J, Mikkola J, Salpakari J. Review of energy system flexibility measures to enable high levels of variable renewable electricity. Renewable and Sustainable Energy Reviews 2015; 45: 785-807.

[5] Daugherty MK, Carter VR. Renewable energy technology. Technology and Engineering Teacher 2010; 69(5): 24.

[6] Patterson M, Macia NF, Kannan AM. Hybrid microgrid model based on solar photovoltaic battery fuel cell system for intermittent load applications. IEEE Transactions on Energy Conversion 2015; 30(1): 359-366.

[7] Pellet N, Giordano F, Ibrahim Dar M, Gregori G, Zakeeruddin SM, Maier J, Grätzel M. Hill climbing hysteresis of perovskite-based solar cells: a maximum power point tracking investigation. Progress in Photovoltaics Research and Applications 2017; 25(11): 42-950.

[8] Abushnaf J, Rassau A. Impact of energy management system on the sizing of a grid-connected PV/Battery system. The Electricity Journal 2018; 31(2): 58-66.

[9] Ahmed J, Salam Z. An improved perturb and observe (P\&O) maximum power point tracking (MPPT) algorithm for higher efficiency. Applied Energy 2015; 150: 97-108.

[10] Mumtaz S, Ahmad S, Khan L, Ali S, Kamal T, Hassan SZ. Adaptive Feedback Linearization Based NeuroFuzzy Maximum Power Point Tracking for a Photovoltaic System. Energies 2018; 11(3): 606.

[11] Wu Z, Yu D, Kang X. Application of improved chicken swarm optimization for MPPT in photovoltaic system. Optimal Control Applications and Methods 2018; 39(2): 1029-1042.

[12] Montecucco A, Knox AR. Maximum power point tracking converter based on the open-circuit voltage method for thermoelectric generators. IEEE Transactions on Power Electronics 2015; 30(2): 828-839.

[13] Sher HA, Murtaza AF, Noman A, Addoweesh KE, Al-Haddad K, Chiaberge M. A New sensorless hybrid MPPT algorithm based on fractional short-circuit current measurement and P\&O MPPT. IEEE Transactions on Sustainable Energy 2015; 6(4): 1426-1434.

[14] Boumaaraf H, Talha A, Bouhali O. A three-phase NPC grid-connected inverter for photovoltaic applications using neural network MPPT. Renewable and Sustainable Energy Reviews 2015; 49: 1171-1179.

[15] Gandoman FH, Ahmadi A, Sharaf AM, Siano P, Pou J, Hredzak B, Agelidis VG. Review of FACTS technologies and applications for power quality in smart grids with renewable energy systems. Renewable and Sustainable Energy Reviews 2018; 82: 502-514.

[16] Rezvani A, Izadbakhsh M, Gandomkar M, Vafaei S. Investigation of ANN-GA and modified perturb and observe MPPT techniques for photovoltaic system in the grid connected mode. Indian Journal of Science and Technology 2015; 8(1): 87-95.

[17] Shah R, Mithulananthan N, Bansal RC, Ramachandaramurthy VK. A review of key power system stability challenges for large-scale PV integration. Renewable and Sustainable Energy Reviews 2015; 41: 1423-1436. 
[18] Garnier C, Muneer T, Currie J. Numerical and empirical evaluation of a novel building integrated collector storage solar water heater. Renewable Energy 2018; 126: 281-295.

[19] Bendib B, Belmili H, Krim F. A survey of the most used MPPT methods: Conventional and advanced algorithms applied for photovoltaic systems. Renewable and Sustainable Energy Reviews 2015; 45: 637-648.

[20] Rezk H, Eltamaly AM. A comprehensive comparison of different MPPT techniques for photovoltaic systems. Solar energy 2015; 112: 1-11. 